\title{
Elevational patterns of the percentages of plant genera with tropical and temperate affinities in Nepal
}

\author{
Yunyun Lai ${ }^{1}$, Jianmeng Feng ${ }^{\text {Corresp. } 1}$ \\ ${ }^{1}$ School of Life Science and Agriculture, Dali University, Dali, Yunnan, China \\ Corresponding Author: Jianmeng Feng \\ Email address: fjm@pku.org.cn
}

Background Geographical patterns of species diversity are one of the key topics in biogeography and ecology. The effects of biogeographical affinities on the elevational patterns of species diversity have attracted much attention recently, but the factors driving elevational patterns of the percentages of plants with tropical and temperate biogeographical affinities have not been adequately explored. Methods We first used univariate least squares regressions (LSR) to evaluate the effects of each predictor on the elevational patterns of the percentages of plant genera with tropical and temperate affinities in Nepal. Then, the lowest corrected Akaike information criterion (AICc) value was used to find the best-fit models for all possible combinations of the aforementioned predictors. We also conducted partial regression analysis to investigate the relative influences of each predictor in the best-fit model of the percentages of plant genera with tropical and temperate affinities. Results With the increase of elevation, the percentage of plant genera with tropical affinity significantly decreased, while that of plant genera with temperate affinity increased. The strongest predictor of the percentages of plant genera with tropical affinity in the examined area was the minimum temperature of the coldest month (MTCM). For the elevational patterns of the percentages of plant genera with temperate affinity, the strongest predictor was the maximum temperature of the warmest month (MTWM). Compared with mid-domain effects (MDE), climatic factors explained much more of the elevational variation of the percentages of plant genera with tropical and temperate affinities. Discussion The elevational patterns of the percentages of plant genera with tropical affinities and the factors driving them supported the revision of the freezing-tolerance hypothesis. That is, freezing may filter out plant genera with tropical affinity, resulting in the decrease of their percentages, with winter coldness playing a predominate role. Winter coldness may not only exert filtering effects on plant genera with tropical affinity, but also regulate the interactions between plant genera with tropical and temperate affinities. The elevational patterns of tropical and temperate plant diversities, and those of their percentages, might be controlled by different factors or mechanisms. 
Freezing-tolerance and the interactions between plant genera with tropical and temperate affinities regulated by climatic factors played stronger roles than MDE in shaping the elevational patterns of the percentages of plant genera with tropical and temperate affinities in Nepal. 
2 Article title:

3 Elevational patterns of the percentages of plant genera with tropical and temperate affinities in

$4 \quad$ Nepal

5 Authors:

6 Yunyun Lai, Jianmeng Feng*

7 Affiliations:

8 Department of Life Science and Agriculture, Dali University, Dali, Yunnan Province, P. R.

9 China

$10 *$ Corresponding Author

11 Jianmeng Feng, E-mail: fjm@pku.org.cn

12

13

14

15

16

17

18

19

20

21

Peer] reviewing PDF | (2018:05:28075:2:0:NEW 8 Nov 2018) 


\section{Abstract:}

24 Background Geographical patterns of species diversity are one of the key topics in biogeography and ecology. The effects of biogeographical affinities on the elevational patterns of species diversity have attracted much attention recently, but the factors driving elevational patterns of the percentages of plants with tropical and temperate biogeographical affinities have not been adequately explored.

Methods We first used univariate least squares regressions (LSR) to evaluate the effects of each predictor on the elevational patterns of the percentages of plant genera with tropical and temperate affinities in Nepal. Then, the lowest corrected Akaike information criterion (AICc) value was used to find the best-fit models for all possible combinations of the aforementioned predictors. We also conducted partial regression analysis to investigate the relative influences of each predictor in the best-fit model of the percentages of plant genera with tropical and temperate affinities.

Results With the increase of elevation, the percentage of plant genera with tropical affinity significantly decreased, while that of plant genera with temperate affinity increased. The strongest predictor of the percentages of plant genera with tropical affinity in the examined area was the minimum temperature of the coldest month (MTCM). For the elevational patterns of the percentages of plant genera with temperate affinity, the strongest predictor was the maximum

41 temperature of the warmest month (MTWM). Compared with mid-domain effects (MDE), climatic factors explained much more of the elevational variation of the percentages of plant 
43 genera with tropical and temperate affinities.

44 Discussion The elevational patterns of the percentages of plant genera with tropical affinities and

45 the factors driving them supported the revision of the freezing-tolerance hypothesis. That is,

46 freezing may filter out plant genera with tropical affinity, resulting in the decrease of their

47 percentages, with winter coldness playing a predominate role. Winter coldness may not only

48 exert filtering effects on plant genera with tropical affinity, but also regulate the interactions

49 between plant genera with tropical and temperate affinities. The elevational patterns of tropical

50 and temperate plant diversities, and those of their percentages, might be controlled by different

51 factors or mechanisms. Freezing-tolerance and the interactions between plant genera with

52 tropical and temperate affinities regulated by climatic factors played stronger roles than MDE in

53 shaping the elevational patterns of the percentages of plant genera with tropical and temperate

54 affinities in Nepal. 


\section{Introduction}

69

Biogeographical affinities of organisms, to a certain extent, reflect their evolutionary history, eco-physiological traits, and adaptation to environmental factors. These affinities may therefore partly determine the distribution patterns of organisms (Latham \& Ricklefs, 1993a; Latham \& Ricklefs, 1993b; Wiens \& Donoghue, 2004; Wang et al., 2011; Feng et al., 2016). For that reason, elevational patterns of diversity and the percentages of plants with one specific biogeographical affinity may differ from those of plants with other biogeographical affinities. However, as far as we know, only the effects of biogeographical affinities on the elevational patterns of species diversity have attracted attention. Relevant studies on this subject showed that although diversity of plants with tropical affinities increased and then decreased with the increase of elevation, showing hump-shaped patterns, it peaked at lower elevation than temperate species diversity (Oommen \& Shanker, 2005; Wang et al., 2007; Feng et al., 2016). This difference may be at least partly due to different biogeographical affinities and related ecophysiological traits, which may modify the influence of water and energy-related variables on the elevational patterns of species diversity (Oommen \& Shanker, 2005; Wang et al., 2007; Feng et al., 2016). We noted that, although several studies showed that the percentages of plant genera with tropical and temperate affinities linearly decreased and increased with the increase of 
85 elevation, respectively (e.g., Wang et al. 2007; Feng \& Xu, 2008a; Feng \& Xu, 2008b; Xu \&

Feng, 2010), the associated controlling factors or underlying mechanisms have been poorly tested statistically. For example, as elevation has long been considered as a proxy of energy gradient, the decreasing trends of the percentages of warmth preferring plants with tropical affinity may be highly linked with energy factors associated with elevation. However, as far as we know, this has not been statistically tested.

The hypothesis of mid-domain effects (MDE) suggests that hump-shaped patterns of diversity along elevational gradients are caused by the increasing overlap of species ranges towards the center of the elevational gradients (Colwell \& Lees, 2000; Colwell et al., 2004). Recently, this hypothesis has been pervasively used to explain hump-shaped diversity patterns, although its influence and generality remain debatable (Colwell et al., 2005; Hawkins et al., 2005; Herzog et al., 2005; Kluge et al., 2006). Previous studies in Nepal observed that the relative influences of MDE and climatic factors on species diversity might vary with the biogeographical affinities of plants (Li \& Feng, 2015). However, no study conducted so far has investigated their relative roles on the elevational patterns of the percentages of plants with tropical and temperate affinities.

The freezing-tolerance hypothesis states that winter coldness may primarily determine spatial patterns of species diversity because most clades evolved in tropical-like climate or have tropical affinities and hence could hardly disperse into cold, temperate regions; compared with that of temperate affinities, the richness of the species with tropical affinities may be more strongly influenced by winter coldness (Latham \& Ricklefs, 1993a; Latham \& Ricklefs, 1993b; Wiens \& 
106

107

108

109

110

111

112

113

114

115

116

117

118

119

120

121

122

123

124

125

126

Donoghue, 2004; Wang et al., 2011). Based on this hypothesis, with increasing elevation, which is a negative proxy of energy, tropical plant diversity may decrease, and winter coldness may be a driver of it. However, not all relevant studies have supported this hypothesis. For example, in Nepal, Li and Feng (2015) found hump-shaped patterns of tropical plant diversity on an elevational gradient, and this effect was mainly controlled by water availability. In addition, Wang et al. (2007) also observed hump-shaped elevational patterns of tropical plant diversity in Gaoligong Mountains, Southeast Tibet, and these were mainly controlled by area and MDE. In the present study, we proposed and corroborated a revised version of the freezing-tolerance hypothesis, which asserts that freezing may filer out plants with tropical affinity, resulting in a decrease in their percentage in regional floras along elevational gradients and that winter coldness may play predominant roles in this pattern. Given this revised version of the freezingtolerance hypothesis, the percentage of plant genera with tropical affinity may decrease with the increase of elevation and freezing effects.

In the present study, we investigated the elevational patterns of the percentages of plant genera with tropical and temperate affinities in Nepal and associated controlling factors. We aimed to obtain the relative roles of MDE and climatic factors on the elevational patterns of tropical and temperate plant percentages, and to test a following hypothesis: the elevational patterns shown by the percentages of plant genera with tropical affinity may support the predictions of the revised version of the freezing-tolerance hypothesis.

\section{Materials \& Methods}

\section{Study area}


127 Our study area covered $157,130 \mathrm{~km}^{2}$ in the region between 300 and 5,700 $\mathrm{m}$ a.s.1., located on

128 the southern slopes of the Himalayas in Nepal (Figure 1). In the south to north direction, the

129 elevation increases from roughly $300 \mathrm{~m}$ a.s.1. to more than 5,700 $\mathrm{m}$ a.s.1., and environmental

130 energy decreases by $0.55^{\circ} \mathrm{C}$ per $100 \mathrm{~m}$ of elevation from approximately $19.4^{\circ} \mathrm{C}$ at $1000 \mathrm{~m}$ a.s.l.

131 (Feng et al., 2016). Annual precipitation at 1,600-1,700 $\mathrm{m}$ a.s.l. is high, and it decreases with

132 increasing elevation; all seasonal variables (i.e., seasonal temperature, seasonal precipitation and

133 annual temperature range) show open-upward-parabola patterns, i.e., decreasing and then

134 increasing along the elevational gradient from 300 to 5,700 m a.s.l (Feng et al., 2016). In South

135 Nepal, regions below 2,000 m a.s.1. are mainly characterized by subtropical climate; in Central

136 Nepal, regions between 2,000 and 4,000 $\mathrm{m}$ a.s.1. are primarily dominated by temperate or warm

137 temperate climate; and in North Nepal regions above 4,000 m a.s.l. have an alpine climate

138 (Dobremez, 1976; Bhattarai \& Vetaas, 2003). Consistently, with the increase in latitude and

139 elevation, vegetation changes from subtropical to warm temperate, temperate, and eventually

140 alpine (Dobremez, 1976; Bhattarai \& Vetaas, 2003).

\section{Plant data}

142 Species identity, genus, and family, as well as the minimum and maximum elevation of each

143 species, were obtained from the online version of the Annotated Checklist of the Flowering

144 Plants of Nepal (Press, Shrestha \& Sutton, 2016). In the study, all varieties and subspecies were

145 considered as separate species. To eliminate or reduce the effect of human disturbance at low

146 elevations and low sampling effort at high elevation, we only considered plants sampled between

147300 and 5,700 $\mathrm{m}$ a.s.1., i.e., 4,759 species, belonging to 1,382 genera and 218 families. 


\section{Biogeographical affinities}

We consulted Wu's (1991) dictionary to determine the biogeographical affinities of seed plant genera in Nepal. In this classification system, the biogeographical affinities of genera are primarily defined or determined based on their biogeographical history, fossil records, and modern distribution centers, in particular. For example, if the distribution center of a given genus is in a tropical region, such as a tropical rainforest climate zone, tropical monsoon climate zone, tropical wet and dry or savanna climate zone, or hot desert, this genus is designated a tropical genus or genus with tropical affinities. As the study area was adjacent to China, and the two regions more likely belong to the Eurasian Plate than to the Indian Plate biogeographical zone, this system of biogeographical affinities might be applied to Nepal, as suggested in a previous study (Li \& Feng, 2015). In addition, we consulted the system of biogeographical affinities created by Wielgorskaya (1995). We found that more than $96.6 \%$ of the biogeographical affinities (tropical or temperate affinity) of seed plant genera in China defined by Wu's system (1991) were consistent to those determined by the system developed by Wielgorskaya (1995). For 43 genera whose biogeographical affinities miss in the Wu's biogeographical affinities, we used the system of biogeographical affinities created by Wielgorskaya (1995) to determined their biogeographical affinities. Our approach was thus similar to that used in a variety of studies (Qian, 1999; Qian, 2001; Wang et al., 2011; Li \& Feng, 2015) that drew robust conclusions. Overall, we obtained 710 plant genera with tropical affinities and 516 plant genera with temperate affinity between 300 and 5,700 $\mathrm{m}$ a.s.1. in Nepal. As the number of plant genera with tropical and temperate affinities composed $88.7 \%$ of the total number of genera, we only 
considered genera with tropical and temperate biogeographical affinities in the present study.

\section{Interpolation of plant occurrence}

The occurrence of each genus present between 300 and 5,700 $\mathrm{m}$ a.s.1. was interpolated based on the recorded elevational range of each genus to obtain the number of tropical, temperate and total genera in each 100-m elevation band (e.g., 300-400 m a.s.1., 400-500 m a.s.1.) for a total of 54 elevational bands. This method, which has been frequently used in previous studies (Rahbek, 1997; Grytnes \& Vetaas, 2002), assumed that the genera were distributed continuously between their minimum and maximum elevations (i.e., present in every $100-\mathrm{m}$ vertical band). Then, we estimated the percentage of plant genera with tropical and temperate affinities in each elevational band. The percentage of the plant genera with tropical and temperate affinities was calculated as the ratio between the numbers of plant genera with tropical and temperate affinities and the total number of genera in each elevational band, respectively, and each ratio was multiplied by 100 . The percentages were log-transformed to improve data normality.

\section{Predictors on elevation}

The three categories of climatic variables used in the present study were as follows: (i) energy availability, represented by the mean annual temperature $\left(\mathrm{MAT},{ }^{\circ} \mathrm{C}\right)$, mean temperature of the coldest quarter $\left(\mathrm{MTCQ},{ }^{\circ} \mathrm{C}\right)$, mean temperature of the warmest quarter $\left(\mathrm{MTWQ},{ }^{\circ} \mathrm{C}\right)$, mean temperature of the driest quarter (MTDRYQ, ${ }^{\circ} \mathrm{C}$ ), maximum temperature of the warmest month (MTWM, ${ }^{\circ} \mathrm{C}$ ), and minimum temperature of the coldest month (MTCM, ${ }^{\circ} \mathrm{C}$ ) (Figure 2); (ii) water availability, comprising mean annual precipitation (MAP, $\mathrm{mm}$ ), precipitation in the driest quarter (PDQ, mm), precipitation in the warmest quarter (PWARMQ, mm), and precipitation in 
190 the wettest quarter (PWETQ, mm) (Figure 2); (iii) climatic seasonality, indicated by the annual

191 range of temperature $\left(\mathrm{ART},{ }^{\circ} \mathrm{C}\right.$; maximum temperature of the warmest month - minimum

192 temperature of the coldest month), annual range of precipitation (ARP, mm; precipitation in the

193 wettest month - precipitation in the driest month), temperature seasonality (TSN, ${ }^{\circ} \mathrm{C}$ ), and

194 precipitation seasonality (PSN, mm; coefficient of variation of the mean monthly precipitation)

195 (Figure 2). In addition to the climatic factors, we also included the plant percentages generated

196 by MDE in the present study which were tropical plant percentages generated by MDE

197 (TRPMDE) and temperate plant percentages generated by MDE (TEPMDE) (Figure 3). All

198 climatic data (1970-2000) were downloaded from WorldClim at a resolution of 30 arc-second

199 (ca. $1 \mathrm{~km}$ at the equator) (Hijmans et al. 2005). Although this dataset was derived through spatial

200 interpolation, it could reliably reflect elevational variation of the climatic factors, as confirmed

201 by Qian (2014) and in studies on elevational patterns of plant diversity in Nepal (Li \& Feng 2015;

202 Feng et al. 2016). We used the Mid-Domain Null Program (McCain, 2004) to predict null

203 percentages of plant genera with tropical and temperate affinities, respectively. Firstly, we

204 simulated genus richness over the elevational gradient for total, plant genera with tropical and

205 temperate affinities separately. To eliminate bias caused by the differences between theoretical

206 frequency distributions of range sizes and the observed ones, we used observed range sizes

207 without replacement and randomly chosen range midpoints to produce ranges within the domain

208 limits. Then, we estimated null elevational percentages of plant genera with tropical and

209 temperate affinities as predicted by MDE separately (Figure 3). The percentages of plant genera

210 with tropical and temperate affinity as predicted by MDE were calculated as the ratio between 
211 the numbers of plant genera with tropical and temperate affinities predicted by MDE and the

212 total number of genera predicted by MDE in each elevational band, respectively, and each ratio

213 was multiplied by 100 .

\section{Statistical methods}

215 All the statistical analyses were performed using SAM v4.0 (Rangel, Diniz-Filho \& Bini, 2010). We first used univariate least squares regression (LSR) to evaluate the effects of the three categories of climatic factors on the elevational patterns of the percentages of plant genera with tropical and temperate affinities, respectively. We generated regression models of all possible combinations of the aforementioned predictors, and then we found the best-fit models on the basis of the lowest possible corrected Akaike information criterion $\left(\mathrm{AIC}_{\mathrm{c}}\right)$ values, which deals with the trade-off between the goodness of fit of the model and its simplicity (Burnham \& only the best predictor in each predictor group in univariate LSR models could be candidate, thereby reducing or avoiding multicollinearity among predictors in the same predictor group; (2) only the predictor showing significant effects in univariate LSR models was allowed to enter the model; (3) the predictor showing the highest explanatory power in all univariate LSR models was included in all of the best-fit models. Following Burnham \& Anderson (2002), the model wih the lowest $\mathrm{AIC}_{\mathrm{c}}$ was defined as the best model, and if a model with $\Delta \mathrm{AIC}_{\mathrm{c}}<2$ in comparison with the best-fit model, it was considered equally good fit to the best-fit model.

230 Residual dependence resulting from spatial autocorrelation in ecological data may cause inflated type I errors which may inflate significance level of statistical tests (Lennon, 2000). 
232 Therefore, spatial linear autoregressive models (SLMs) were frequently used to account for the

233 inflated significance level. However, our major topic was not the significance levels but rather

234 the explanatory powers of the predictors. In addition, the influence of predictors derived from

235 SLMs may depend on the scales of spatial structures; the influences of predictors on large or

236 small-scale spatial structures may be underestimated or overestimated, respectively (Diniz-Filho,

237 Bini \& Hawkins, 2003). Therefore, SLMs were not used in the present study.

\section{Results}

239 The percentage of plant genera with tropical affinity along the elevational gradient

240 significantly decreased from more than $80 \%$ to close to zero, while that of plant genera with

241 temperate affinity increased with the increase of elevation (Figure 4). The univariate regressions

242 models showed that MTCM was the strongest predictor among the energy variables for the

243 percentage of plant genera with tropical affinity (98.6\% of the variation explained) along the

244 elevational gradient; MAP (91.3\%) and PSN (71.4\%) were the strongest predictors in the

245 category of water variables and climatic seasonality variables, respectively (Table 1). Therefore,

246 MTCM, a factor representing winter freezing, was selected as the best predictors for the

247 elevational patterns of the percentage of plant genera with tropical affinity. For the percentage of

248 plant genera with temperate affinity, MTWM was the strongest predictor among the energy

249 variables $(87.7 \%$ of the variation explained), while PWETQ $(84.6 \%)$ and PSN (86.3\%) were the

250 strongest predictors in the categories of water variables and climatic seasonality variables,

251 respectively (Table 1). The univariate regressions models showed that neither TRPMDE nor

252 TEPMDE showed significant effects on the elevational variation of the percentage of plant 
253 genera with tropical affinity (Table 1). Therefore, no predictor from the category of the 254 percentages generated by MDE was selected as candidate in the $\mathrm{AIC}_{\mathrm{c}}$ based best-fit models for 255 the percentages of plant genera with tropical affinity. Neither TRPMDE nor TEPMDE showed high explanatory power on the elevational variation of the percentages of plant genera with temperate affinity $(26.5 \%(P<0.01)$ and $11.2 \%(P<0.05)$, respectively) (Table 1$)$, but TEPMDE from the category of the percentages generated by MDE was selected as a candidate in the $\mathrm{AIC}_{\mathrm{c}}$ based best-fit model for the percentage of plant genera with temperate affinity.

The $\mathrm{AIC}_{\mathrm{c}}$ based model selection showed that for the percentages of plant genera with tropical affinity there were two equally-good multiple regressions models (S1). The first comprised

MTCM and MAP $\left(\triangle \mathrm{AIC}_{\mathrm{c}}=0\right)$, and $98.8 \%$ of the variation was explained $(\mathrm{S} 1)$. The second comprised MTCM, MAP and PSN $\left(\triangle \mathrm{AIC}_{\mathrm{c}}=1.7\right)$, and $99.8 \%$ of the variation was explained $(\mathrm{S} 1)$.

For the percentages of plant genera with temperate affinity the best multiple regressions model comprised MTWM, PSN and TEPMDE, and 96.2\% of the variation was explained (S1). plant genera with tropical affinity showed that MTCM totally and independently explained $98.6 \%$ and $7.5 \%$ of the elevational variation of the percentages of plant genera with tropical affinity, respectively, while for MAP, the total and independent percentages explained were $91.3 \%$ and $0.2 \%$, respectively (Figure 5). The total and shared percentage explained were $98.8 \%$ and $91.1 \%$, respectively (Figure 5).

272 Partial regression analyses using variables from the second best models for the percentages of 273 plant genera with tropical affinity showed that MTCM totally and independently explained 
$27498.6 \%$ and $6.9 \%$ of the elevational variation of the percentages of plant genera with tropical

275 affinity, respectively (Figure 6); MAP totally and independently explained $91.3 \%$ and $0.2 \%$ of 276 the elevational variation, respectively; PSN totally and independently explained $71.4 \%$ and $277<0.1 \%$ of the elevational variation, respectively. Their total and shared percentage explained was $278 \quad 98.8 \%$ and $70.7 \%$, respectively (Figure 6).

279 Partial regression analyses showed that, compared to PSN and TEPMDE, MTWM totally and 280 independently explained much more of the elevational variation of the percentage of temperate genera $(87.7 \%$ and $9.6 \%$ VS $86.3 \%$ and $0.7 \%$, and VS $26.5 \%$ and $3.2 \%$, respectively) (Figure 7 ).

282 Partial regression analyses also showed that, compared to percentages generated by MDE 283 (represented by TEPMDE), climatic factors (represented by MTWM and PSN) totally and independently explained much more of the elevation variation observed in the percentage of plant genera with temperate affinity (93\% and 69.7\% VS $26.5 \%$ and 3.2\%, respectively) (Figure

8).

\section{Discussion}

The present study showed that with the increase of elevation, the percentages of plant genera with tropical affinity decreased, while those of plant genera with temperate affinity increased. Other relevant studies also demonstrated similar trends in the percentages of plant genera with tropical and temperate affinities in East Himalayan regions, e.g., the Gaoligong Mountains

(Wang et al. 2007), Yao Mountains (Feng \& Xu, 2008a), and Nanghun River Nature Reserve

(Feng \& $\mathrm{Xu}, 2008 \mathrm{~b}$ ). In addition, no study conducted so far observed different elevational

patterns in the percentages of plant genera with tropical and temperate affinities from the trends 
295

296

297

298

299

300

301

302

303

304

305

306

307

308

309

310

311

312

313

314

315

observed here. Therefore, the contrasting linear trends of the percentages of plant genera with tropical and temperate affinities on elevation might be a universal rule, especially in the Himalayan regions, though further studies are needed in the future to corroborate this notion.

Although a variety of climatic factors, including energy, water and seasonal factors, strongly affected the elevational patterns of the percentage of plant genera with tropical affinity, energy variables played the strongest roles, especially MTCM, representing winter coldness. These effects may be linked to the eco-physiological traits inherited from the biogeographical affinities of the tropical plants. Most plant genera with tropical affinity originated from and evolved in tropical regions, and prefer a warm climate or habitat (Latham \& Ricklefs, 1993a; Latham \& Ricklefs, 1993b; Wiens \& Donoghue, 2004; Wang et al., 2011). Therefore, with increasing elevation, plant genera with tropical affinity may be gradually filtered out of the biomes by increasing freezing effects. It may suggest that the elevational patterns of the percentages of plant genera with tropical affinity and factors driving them supported the revision of the freezing-tolerance hypothesis.

Interactions between plant genera with tropical and temperate affinities may also play important roles in shaping the contrasting patterns of the percentages of plant genera with tropical and temperate affinities along elevation. With the increasing elevation, increasing freezing may result in the decrease of habitat suitability for plant genera with tropical affinity, while plant genera with temperate affinity, which have stronger freezing tolerability and weaker warmth tolerability than plant genera with tropical affinity, gain competitive ability for habitat against plant genera with tropical affinity. We thus observed decreasing and increasing trends in 
316 the percentage of plant genera with tropical and temperate affinities with elevation, respectively,

317 in which climatic gradients, especially the gradients of the factors representing freezing and

318 warmth effects, regulate the interactions between plant genera with tropical and temperate

319 affinities. Thus, we suggested that the research of the elevational patterns of the percentages of

320 plant genera with tropical and temperate affinities should consider the roles of both abiotic

321 filtering effects and biotic interactions between plant genera with tropical and temperate

322 affinities.

323 Water availability played the strongest roles in the hump-shaped diversity patterns of plant

324 genera with tropical affinity in the similar elevational gradient in Nepal (Li \& Feng, 2015). In

325 contrast, in the present study, biotic competition and winter freezing may have played important

326 roles in the decreasing percentages of plant genera with tropical affinity along the elevational

327 gradient. Also, in Nepal energy availability in quadratic models strongly shaped the hump-

328 shaped patterns of genus richness of plant genera with temperate affinity along similar

329 elevational gradient (Li \& Feng, 2015). Nonetheless, in the present study, all energy variables in

330 their linear forms played strong roles in the increasing percentages of temperate plant genera.

331 This may imply that energy variables play different roles in shaping elevational patterns of the

332 percentages and richness of plant genera with temperate affinities. The quadratic terms of energy

333 variables for the diversity of plant genera with temperate affinity may reflect the eco-

334 physiological traits of plant genera with temperate affinity and their adaptation to the energy

335 gradients on elevation. The linear terms of energy variables (especially MTWM) for the

336 percentages of plant genera with temperate affinity may imply the elevational variation of 
337

338

339

340

341

342

343

344

competition between plant genera with tropical and temperate affinities. Overall, the elevational patterns of tropical and temperate diversities and percentages may also be controlled by different mechanisms.

Previous studies suggested that plant genera with tropical affinity could be observed in high altitude, and plant genera with temperate affinity could occur at low altitude (Wang et al., 2007; Li \& Feng, 2015; Feng et al., 2016), although their proportions might be lower than that at low and high altitude, respectively. Thus, although plant genera with temperate affinity may survive warm climates and plant genera with tropical affinity may survive cool or cold climate, they have lower competitive ability than plant genera with tropical and temperate affinities in such habitats, respectively. Therefore, we suggest that the percentages of plant genera with tropical affinity at high altitude and plant genera with temperate affinity at low altitude might be more influenced by the biotic interactions between them than the abiotic filtering effects.

Due to the increasing overlapping of ranges of organisms towards the center of the gradients, the MDE predicted hump-shaped altitudinal biodiversity patterns in the absence of other factors (Colwell \& Lees, 2000; Colwell et al., 2004). In addition, the increasing overlapping towards the center of the gradients might be strengthened by wider ranges of organisms (Colwell et al., 2004; Wang et al., 2007). A previous study in Nepal found that compared with plant genera with tropical affinity, plant genera with temperate affinity had wider elevational ranges (Li \& Feng, 2015). This may imply that the plant genera with temperate affinity examined in the present study might be more strongly affected by MDE than plant genera with tropical affinity, especially around the midpoint of the elevational gradient. Therefore, we observed higher 
358

359

360

361

362

363

364

365

366

367

368

369

370

371

372

373

374

375

376

377

richness of plant genera with temperate affinity around the midpoint of the elevational gradient, which was reflected in the hump-shaped elevational pattern of the percentages of plant genera with temperate affinities, while the percentage of plant genera with tropical affinity evidenced a depression-shaped pattern. Our analyses showed that neither hump-shaped elevational pattern of TEPMDE nor the depressed-shaped elevational pattern of TRPMDE showed strong influences on the linear patterns of the percentages of plant genera with tropical or temperate affinities along an elevational gradient in Nepal. In addition, they explained less of the elevational variation of tropical and temperate plant genera percentages than climatic factors, particularly regarding the linear decreasing energy factors on elevation, which might play important roles not only in freezing-tolerance for plant genera with tropical affinity, but also in regulating biotic interactions between plant genera with tropical and temperate affinities. Therefore, freezingtolerance and the interactions between plant genera with tropical and temperate affinities regulated by climatic factors played stronger roles than MDE in the elevational patterns of tropical and temperate plant genera percentages in Nepal.

\section{Conclusions}

In the present study, we investigated the influences of climatic factors on the elevational patterns of the percentages of plant genera with tropical and temperate affinities in Nepal, and tested the revised version of the freezing-tolerance hypothesis for plant genera with tropical affinities. We found that the decreasing trends of the percentages of tropical plant genera with increasing elevation were mainly controlled by MTCM, supporting the revised version of the freezing-tolerance hypothesis. The elevational patterns of diversities and percentages of plant 
379

380

381

382

383

384

385

386

387

388

389

390

391

392

393

394

395

396

397

398

399

genera with tropical and temperate affinities are likely controlled by different factors or mechanisms. Climatic factors played stronger roles than MDE in the elevational patterns of tropical and temperate plant genera percentages in Nepal.

\section{Acknowledgments}

We would like to thank Fengshu Zha, Zhao Zhang, and Renyong Nan for their time and expertise during the preparation of this manuscript.

\section{References}

Bhattarai KR, Vetaas OR. 2003. Variation in plant species richness of different life forms along a subtropical elevation gradient in the Himalayas, east Nepal. Global Ecology and Biogeography 12: 327-340 DOI: 10.1046/j.1466-822X.2003.00044.x

Burnham KP, Anderson DR. 2002. Model selection and multimodel inference: a practical informationtheoretic approach. New York: Springer. 1-488.

Colwell RK, Lees DC. 2000. The mid-domain effect: geometric constraints on the geography of species diversity. Trends in Ecology \& Evolution 15: 70-76 DOI: 10.1016/S0169$5347(99) 01767-X$

Colwell RK, Rahbek C, Gotelli NJ. 2004. The mid-domain effect and species richness patterns: what have we learned so far? The American Naturalist 163: E1-E23 DOI: $10.1086 / 382056$

Colwell RK, Rahbek C, Gotelli NJ. 2005. The mid-domain effect: there's a baby in the bathwater. The American Naturalist 166: E149-E154 DOI: 10.1086/491689

Diniz-Filho JAF, Bini LM, Hawkins BA. 2003. Spatial autocorrelation and red herrings in 

822X.2003.00322.x

402

403

404

405

406

407

408

409

410

411

412

413

414

415

416

417

418

419

420

Dobremez JF. 1976. Le Népal. Ecologie et Biogéographie. Paris: Centre National de la Recherche Scientifique.

Feng JM, Hu XK, Wang J, Wang YM. 2016. Support for the elevational Rapoport's rule among seed plants in Nepal depends on biogeographical affinities and boundary effects. Ecology and Evolution 6: 7246-7252 DOI: 10.1002/ece3.2473

Feng JM, Xu CD. 2008a. Altitudinal patterns of seed plants and floristic composition in Mountain Yao Nature Reserve, Yunnan Province, China. Journal of Wuhan Botanical Research 26: 271-275.

Feng JM, Xu CD. 2008b. Altitudinal patterns of diversity of floristic distribution types in Nangunhe Nature Reserve, Yunnan, China. Journal of Southwest University (Natural Science Edition) 30: 46-50.

Hawkins B A, Diniz-Filho JAF, Weis AE. 2005. The mid-domain effect and diversity gradients: is there anything to learn? The American Naturalist 166: E140-E143 DOI: $10.1086 / 491686$

Herzog SK, Kessler M, Bach K. 2005. The elevational gradient in Andean bird species diversity at the local scale: a foothill peak and a high-elevation plateau. Ecography 28: 209-222 DOI: 10.1111/j.0906-7590.2005.03935.x

Kluge J, Kessler M, Dunn RR. 2006. What drives elevational patterns of diversity? A test of geometric constraints, climate and species pool effects for pteridophytes on an elevational 
gradient in Costa Rica. Global Ecology and Biogeography 15: 358-371 DOI:

Grytnes JA, Vetaas OR. 2002. Species richness and altitude: A comparison between null models and interpolated plant species richness along the Himalayan altitudinal gradient, Nepal. American Naturalist 159: 294-304 DOI: 10.1086/338542

Hijmans RJ, Cameron SE, Parra JL, Jones PG, Jarvis A. 2005. Very high resolution interpolated climate surfaces for global land areas. International Journal of Climatology 25: 1965-1978 DOI: $10.1002 /$ joc. 1276

Latham RE, Ricklefs RE. 1993a. Global Patterns of Tree Species Richness in Moist Forests Energy-Diversity Theory Does Not Account for Variation in Species Richness. Oikos 67: 325-333 DOI: $10.2307 / 3545479$

Latham RE, Ricklefs RE. 1993b. Continental comparisons of temperate-zone tree species diversity. In: Ricklefs RE \& Schluter D, ed. Species diversity in ecological communities: historical and geographical perspectives. Chicago: University of Chicago Press, 294-314.

Lennon JJ. 2000. Red-shifts and red herrings in geographical ecology. Ecography 23: 101-113 DOI: $10.1034 / \mathrm{j} .1600-0587.2000 .230111 . \mathrm{x}$

Li M, Feng JM. 2015. Biogeographical Interpretation of Elevational Patterns of Genus Diversity of Seed Plants in Nepal. Plos One 10: e0140992. doi:10.1371/journal.pone.0140992 DOI: 10.1371/journal.pone.0140992

McCain CM. 2004. The mid-domain effect applied to elevational gradients: species diversity of small mammals in Costa Rica. Journal of Biogeography 31: 19-31 DOI: 10.1046/j.0305- 
0270.2003.00992.x

443

444

445

446

447

448

449

450

451

452

453

454

455

456

457

458

459

460

461

462

Oommen MA, Shanker K. 2005. Elevational species diversity patterns emerge from multiple local mechanisms in Himalayan woody plants. Ecology 86: 3039-3047 DOI: 10.1890/041837

Press JR, Shrestha KK, Sutton DA. 2016. Flora of Nepal (online version). Availaable at http://www.floraofnepal.org (Accessed 25 July 2016).

Qian H. 2014. Contrasting relationships between clade age and temperature along latitudinal versus elevational gradients for woody angiosperms in forests of South America. Journal of Vegetation Science 25: 1208-1215 DOI: 10.1111/jvs.12175

Qian H. 1999. Floristic analysis of vascular plant genera of North America north of Mexico: characteristics of phytogeography. Journal of Biogeography 26: 1307-1321 DOI: 10.1046/j.1365-2699.1999.00367.x

Qian H. 2001. Floristic analysis of vascular plant genera of North America north of Mexico: spatial patterning of phytogeography. Journal of Biogeography 28: 525-534 DOI: 10.1046/j.1365-2699.2001.00560.x

Rahbek C. 1997. The relationship among area, elevation, and regional species richness in neotropical birds. American Naturalist 149: 875-902 DOI: 10.1086/286028

Rangel TF, Diniz-Filho JAF, Bini LM. 2010. SAM: A comprehensive application for Spatial Analysis in Macroecology. Ecography 33: 1-5 DOI: 10.1111/j.1600-0587.2009.06299.x

Wang ZH, Fang JY, Tang ZY, Lin X. 2011. Patterns, determinants and models of woody plant diversity in China. Proceedings of the Royal Society B-Biological Sciences 278: 2122- 
464

465

466

467

468

469

470

471

472

473

474

475

476

477

478

479

480

481

482

483

Wang ZH, Tang ZY, Fang JY. 2007. Altitudinal patterns of seed plant richness in the Gaoligong Mountains, south-east Tibet, China. Diversity and Distributions 13: 845-854 DOI: $10.1111 / \mathrm{j} .1472-4642.2007 .00335 . \mathrm{x}$

Wielgorskaya T. 1995. Dictionary of generic names of seed plants. New York: Columbia University Press.

Wiens JJ, Donoghue MJ. 2004. Historical biogeography, ecology and species richness. Trends in Ecology \& Evolution 19: 639-644 DOI: 10.1016/j.tree.2004.09.011

Wu ZY. 1991. The areal-types of Chinese genera of seed plants. Acta Botanica Yunnanica Suppl. 4: 1-139.

Xu CD, Feng JM. 2010. Altitudinal pattterns of floristci elements of ferns in Ailao Mountain, Yunnan province. Guihaia, 30: 301-305.

5

6

7

8




\section{Tables}

Table 1 Explanatory power of predictors for the percentages of plant genera with tropical and temperate affinities on elevational patterns through univariate regressions models (\%)

\section{Figures}

Figure 1 Location and topography of the study area

Figure 2 Elevational patterns of climatic factors in Nepal

Figure 3 Elevational patterns of the percentages of plant genera with tropical and temperate affinities generated by MDE

Figure 4 Elevational patterns of the percentages of plant genera with tropical and temperate affinities in Nepal

Figure 5 Comparing the explanatory power of MTCM and MAP on the percentages of plant genera with tropical affinity by partial regression with the predictors included in the first best model. A shows the effects of MTCM; B shows the effects of MAP. Total variance explained by $\{\mathrm{A}\}=98.6 \%$; Total variance explained by $\{\mathrm{B}\}=91.3 \%$; Total variance explained by $\{\mathrm{A}+\mathrm{B}\}=$ 98.8\%. [A.B] variance explained by $\{\mathrm{A}\}$ only $=7.5 \%$; [A:B] Variance Sharely explained $=$ $91.1 \%$; [B.A] Variance explained by $\{\mathrm{B}\}$ only $=0.2 \%$; $[1-(\mathrm{A}+\mathrm{B})]$ Unexplained variance $=1.2 \%$. 
516 Figure 6 Comparing the explanatory power of MTCM, MAP and PSN on the percentages of 517 plant genera with tropical affinity by partial regression with the predictors included in the second 518 best model. A shows the effects of MTCM; B shows the effects of MAP; C shows the effects of 519 PSN. $\mathrm{A}=0.986 ; 1-(\mathrm{A})=0.014 ; \quad \mathrm{A} . \mathrm{B}=0.075 ; \mathrm{A}: \mathrm{B}=0.911 ; \mathrm{A} . \mathrm{C}=0.273 ; \mathrm{A}: \mathrm{C}=0.713 ; \mathrm{A} . \mathrm{B}+\mathrm{C}$ $520=0.069 ; \mathrm{A}: \mathrm{B}+\mathrm{C}=0.918 ; \mathrm{B}=0.913 ; 1-(\mathrm{B})=0.087 ; \mathrm{B} \cdot \mathrm{A}=0.002 ; \mathrm{B}: \mathrm{A}=0.911 ; \mathrm{B} \cdot \mathrm{C}=0.206 ; \mathrm{B}: \mathrm{C}$ $521=0.707 ; \mathrm{B} . \mathrm{A}+\mathrm{C}=0.002 ; \mathrm{B}: \mathrm{A}+\mathrm{C}=0.912 ; \mathrm{C}=0.714 ; 1-(\mathrm{C})=0.286 ; \mathrm{C} . \mathrm{A}=<.001 ; \mathrm{C}: \mathrm{A}=0.713$; 522 C. $\mathrm{B}=0.006 ; \mathrm{C}: \mathrm{B}=0.707 ; \mathrm{C} . \mathrm{A}+\mathrm{B}=<.001 ; \mathrm{C}: \mathrm{A}+\mathrm{B}=0.714 ; \mathrm{A}+\mathrm{B}=0.988 ; 1-(\mathrm{A}+\mathrm{B})=0.012$; $523 \mathrm{~A}+\mathrm{B} . \mathrm{C}=0.274 ; \mathrm{A}+\mathrm{B}: \mathrm{C}=0.714 ; \mathrm{A}+\mathrm{C}=0.987 ; 1-(\mathrm{A}+\mathrm{C})=0.013 ; \mathrm{A}+\mathrm{C} . \mathrm{B}=0.075 ; \mathrm{A}+\mathrm{C}: \mathrm{B}=$ $5240.912 ; \mathrm{B}+\mathrm{C}=0.92 ; 1-(\mathrm{B}+\mathrm{C})=0.08 ; \mathrm{B}+\mathrm{C} . \mathrm{A}=0.002 ; \mathrm{B}+\mathrm{C}: \mathrm{A}=0.918 ; \mathrm{A}+\mathrm{B}+\mathrm{C}=0.988 ; 1-$ $(\mathrm{A}+\mathrm{B}+\mathrm{C})=0.012 ; \mathrm{A}: \mathrm{B} \cdot \mathrm{C}=0.204 ; \mathrm{A}: \mathrm{C} \cdot \mathrm{B}=0.006 ; \mathrm{B}: \mathrm{C} \cdot \mathrm{A}=<.001 ; \mathrm{A}: \mathrm{B}: \mathrm{C}=0.707$.

Figure 7 Comparing the explanatory power of MTWM, PSN and TEPMDE on the percentages of plant genera with temperate affinity by partial regression with the predictors included in the best model. A shows the effects of MTCM; B shows the effects of PSN; C shows the effects of TEPMDE. $\mathrm{A}=0.877 ; 1-(\mathrm{A})=0.12 ; \mathrm{A} . \mathrm{B}=0.067 ; \mathrm{A}: \mathrm{B}=0.813 ; \mathrm{A} . \mathrm{C}=0.69 ; \mathrm{A}: \mathrm{C}=0.189 ; \mathrm{A} . \mathrm{B}+\mathrm{C}$ $=0.096 ; \mathrm{A}: \mathrm{B}+\mathrm{C}=0.784 ; \mathrm{B}=0.863 ; 1-(\mathrm{B})=0.137 ; \mathrm{B} . \mathrm{A}=0.05 ; \mathrm{B}: \mathrm{A}=0.813 ; \mathrm{B} . \mathrm{C}=0.601 ; \mathrm{B}: \mathrm{C}$ $=0.262 ; \mathrm{B} . \mathrm{A}+\mathrm{C}=0.007 ; \mathrm{B}: \mathrm{A}+\mathrm{C}=0.856 ; \mathrm{C}=0.265 ; 1-(\mathrm{C})=0.735 ; \mathrm{C} . \mathrm{A}=0.076 ; \mathrm{C}: \mathrm{A}=0.189$; $\mathrm{C} . \mathrm{B}=0.003 ; \mathrm{C}: \mathrm{B}=0.262 ; \mathrm{C} . \mathrm{A}+\mathrm{B}=0.032 ; \quad \mathrm{C}: \mathrm{A}+\mathrm{B}=0.233 ; \mathrm{A}+\mathrm{B}=0.93 ; 1-(\mathrm{A}+\mathrm{B})=0.07$; $\mathrm{A}+\mathrm{B} . \mathrm{C}=0.697 ; \mathrm{A}+\mathrm{B}: \mathrm{C}=0.233 ; \quad \mathrm{A}+\mathrm{C}=0.955 ; 1-(\mathrm{A}+\mathrm{C})=0.045 ; \mathrm{A}+\mathrm{C} \cdot \mathrm{B}=0.099 ; \mathrm{A}+\mathrm{C}: \mathrm{B}=$ $0.856 ; \mathrm{B}+\mathrm{C}=0.866 ; \quad 1-(\mathrm{B}+\mathrm{C})=0.134 ; \mathrm{B}+\mathrm{C} . \mathrm{A}=0.082 ; \mathrm{B}+\mathrm{C}: \mathrm{A}=0.784 ; \mathrm{A}+\mathrm{B}+\mathrm{C}=0.962 ; 1-$

Figure 8 Comparing the explanatory power of climatic factors (MTWM, MAP) and the percentages generated by MDE (TEPMDE) on the percentages of plant genera with temperate affinity by partial regression with the predictors included in the best model. A shows the effects of climatic factors; B shows the effects of MDE. Total variance explained by $\{A\}=93 \%$; Total variance explained by $\{\mathrm{B}\}=26.5 \%$; Total variance explained by $\{\mathrm{A}+\mathrm{B}\}=96.2 \%$. [A.B] variance explained by $\{A\}$ only $=69.7 \%$; [A:B] Variance Sharely explained $=23.3 \%$; [B.A] Variance explained by $\{B\}$ only $=3.2 \% ;[1-(A+B)]$ Unexplained variance $=3.8 \%$. 


\section{Figure 1}

Location and topography of the study area

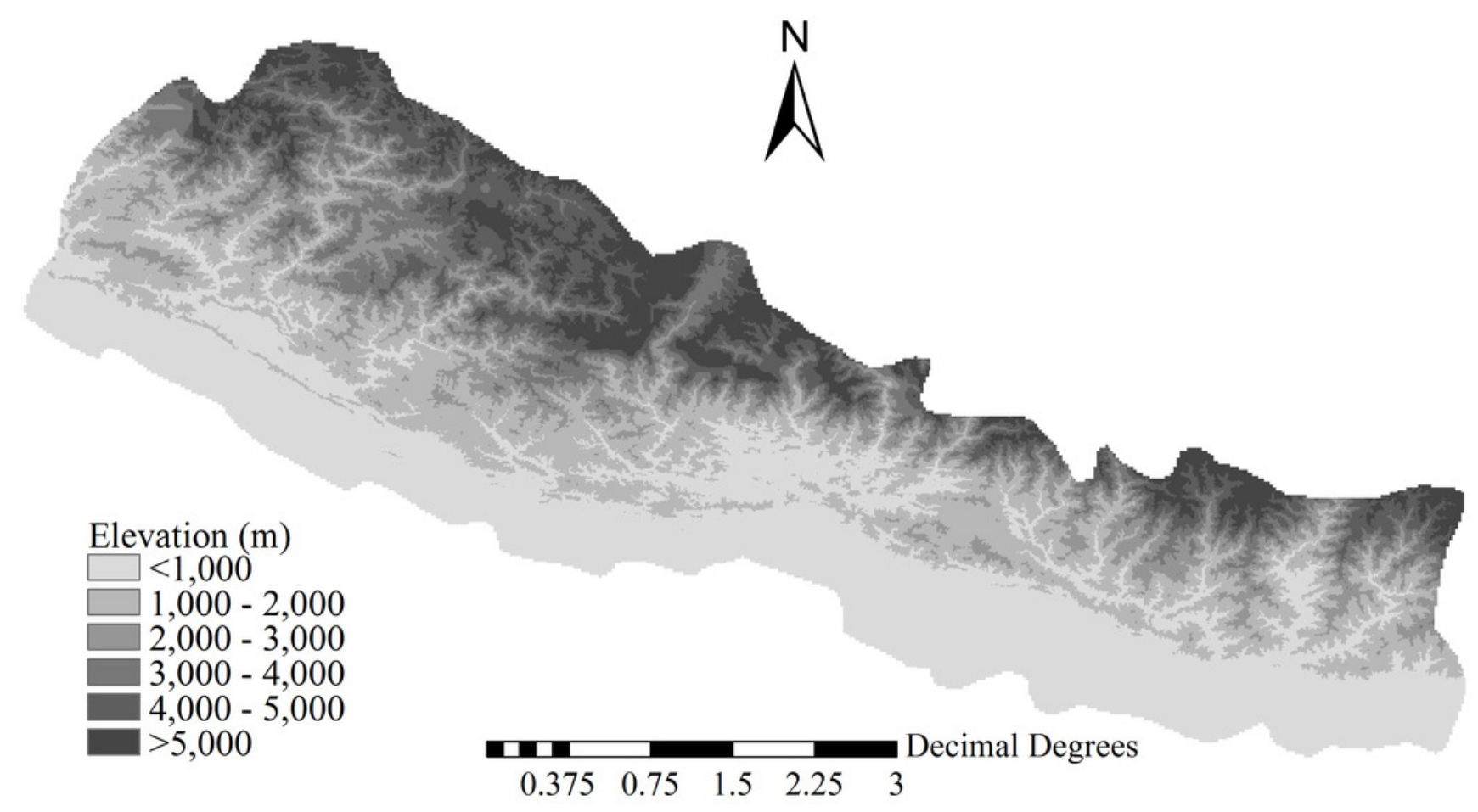


Figure 2 (on next page)

Elevational patterns of climatic factors in Nepal 


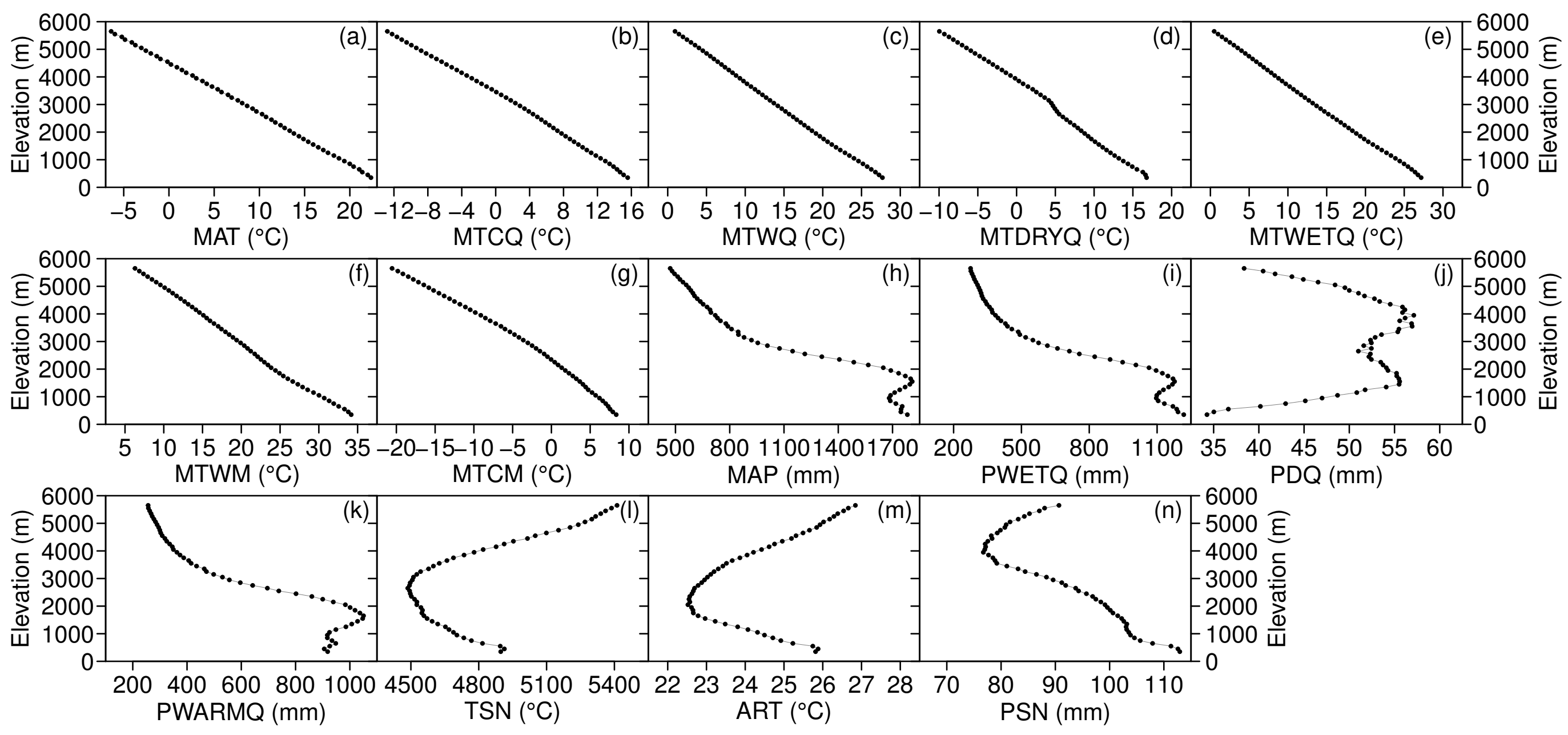


Figure 3

Elevational patterns of the percentages of tropical and temperate genera generated by MDE

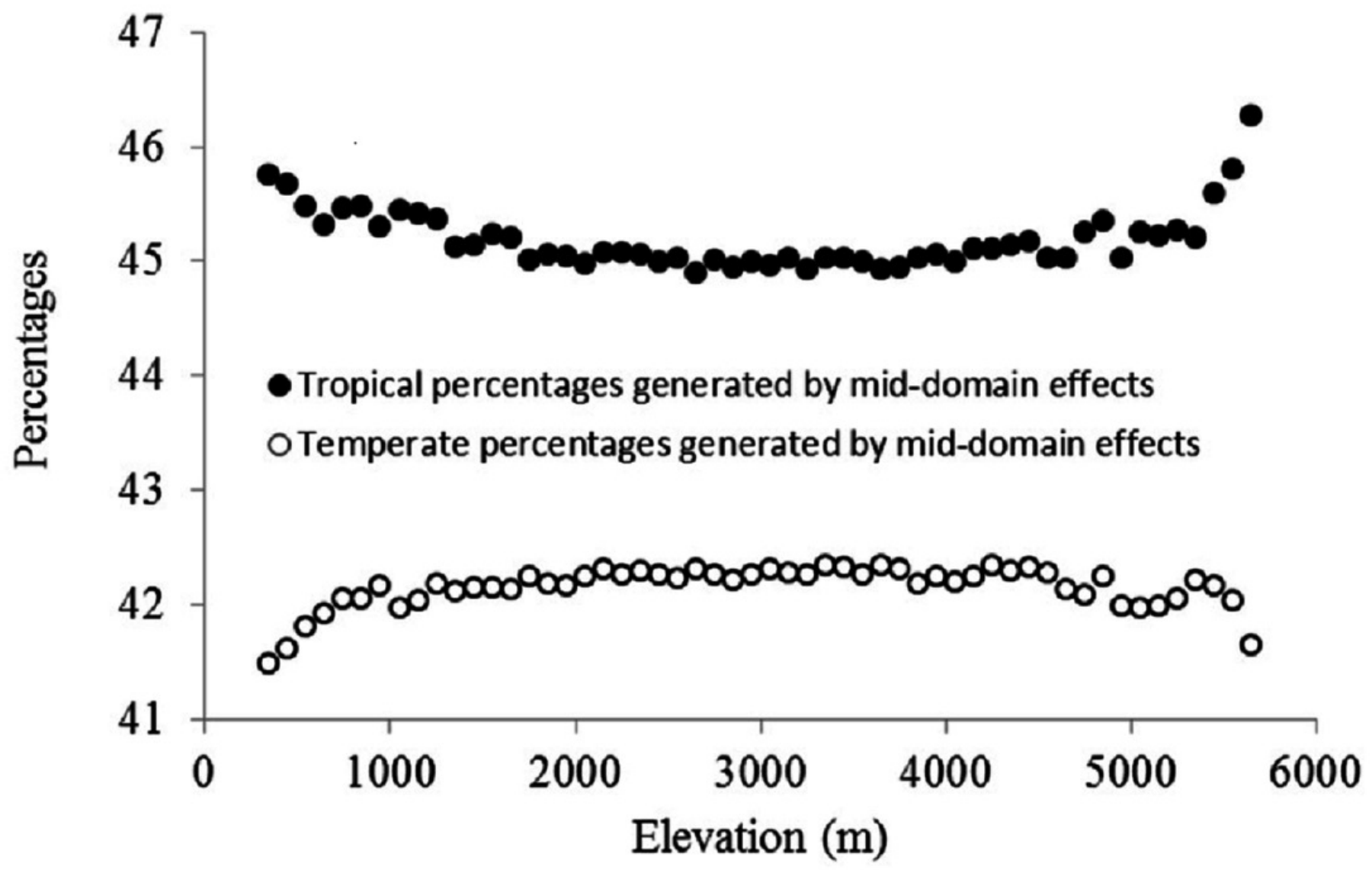


Figure 4

Elevational patterns of the percentages of tropical and temperate genera in Nepal

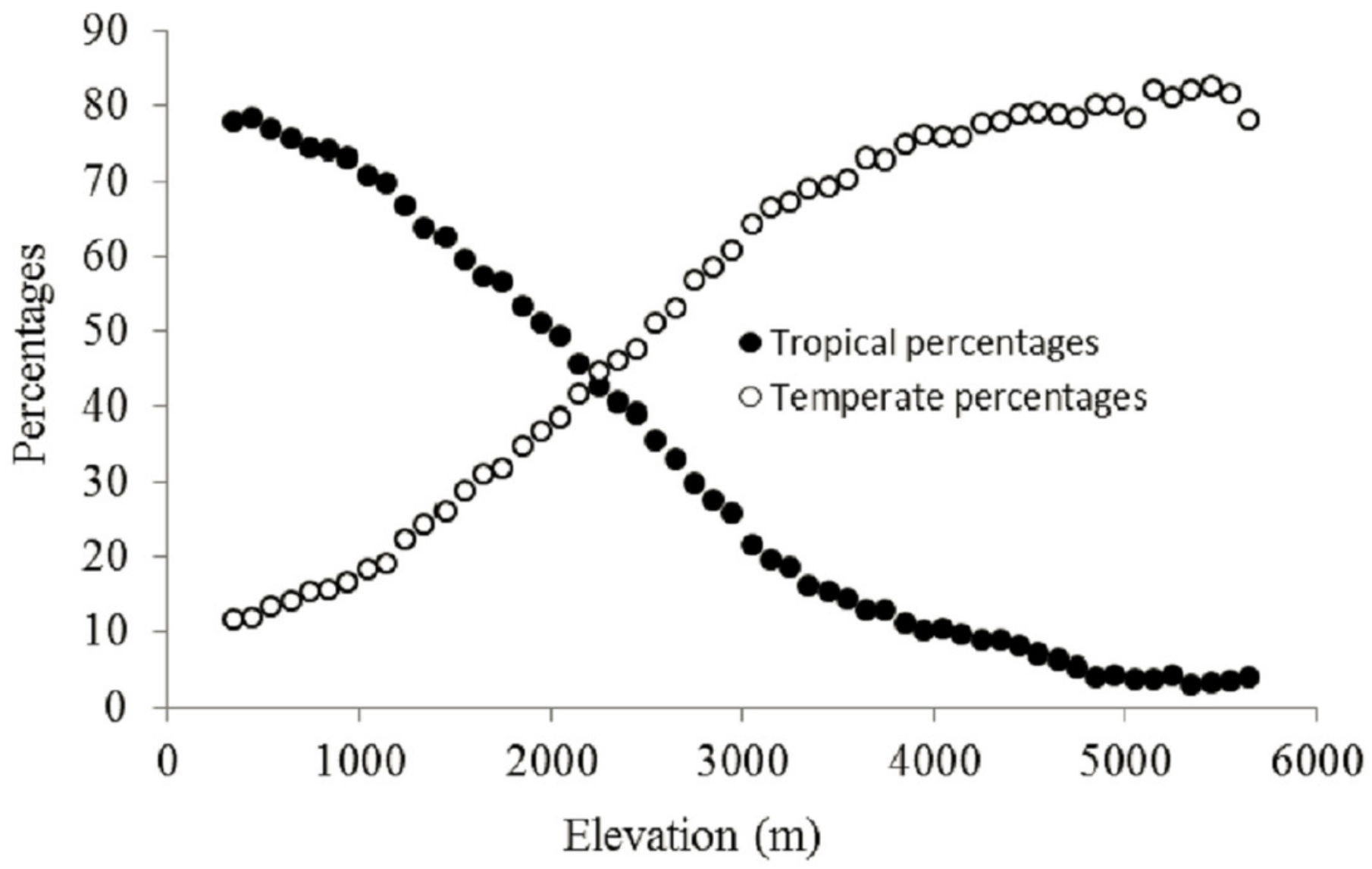




\section{Figure 5}

Comparing the explanatory power of MTCM and MAP on the percentages of plant genera with tropical affinity by partial regression with the predictors included in the first best mode

A shows the effects of MTCM; $B$ shows the effects of MAP. Total variance explained by $\{A\}=$ 98.6\%; Total variance explained by $\{B\}=91.3 \%$; Total variance explained by $\{A+B\}=$ 98.8\%. [A.B] variance explained by $\{A\}$ only $=7.5 \% ;[A: B]$ Variance Sharely explained $=$ 91.1\%; [B.A] Variance explained by $\{B\}$ only $=0.2 \%$; $[1-(A+B)]$ Unexplained variance $=$ $1.2 \%$.

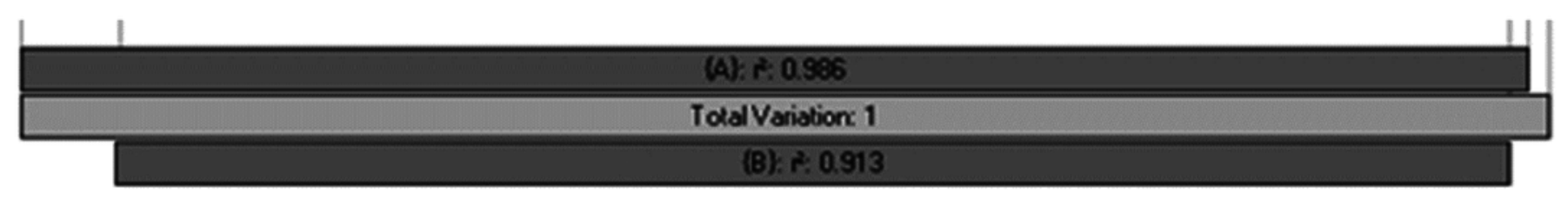




\section{Figure 6}

Comparing the explanatory power of MTCM, MAP and PSN on the percentages of plant genera with tropical affinity by partial regression with the predictors included in the second best model

A shows the effects of MTCM; $B$ shows the effects of MAP; $C$ shows the effects of PSN. $A=$ $0.986 ; 1-(A)=0.014 ; A . B=0.075 ; A: B=0.911 ; A \cdot C=0.273 ; A: C=0.713 ; A . B+C=0.069$; $A: B+C=0.918 ; B=0.913 ; 1-(B)=0.087 ; B . A=0.002 ; B: A=0.911 ; B . C=0.206 ; B: C=$ $0.707 ; B . A+C=0.002 ; B: A+C=0.912 ; C=0.714 ; 1-(C)=0.286 ; C . A=<.001 ; C: A=0.713 ;$ $C . B=0.006 ; C: B=0.707 ; C . A+B=<.001 ; C: A+B=0.714 ; A+B=0.988 ; 1-(A+B)=0.012 ;$ $A+B . C=0.274 ; A+B: C=0.714 ; A+C=0.987 ; 1-(A+C)=0.013 ; A+C \cdot B=0.075 ; A+C: B=$ $0.912 ; B+C=0.92 ; 1-(B+C)=0.08 ; B+C . A=0.002 ; B+C: A=0.918 ; A+B+C=0.988 ; 1-$ $(A+B+C)=0.012 ; A: B \cdot C=0.204 ; A: C \cdot B=0.006 ; B: C \cdot A=<.001 ; A: B: C=0.707$.

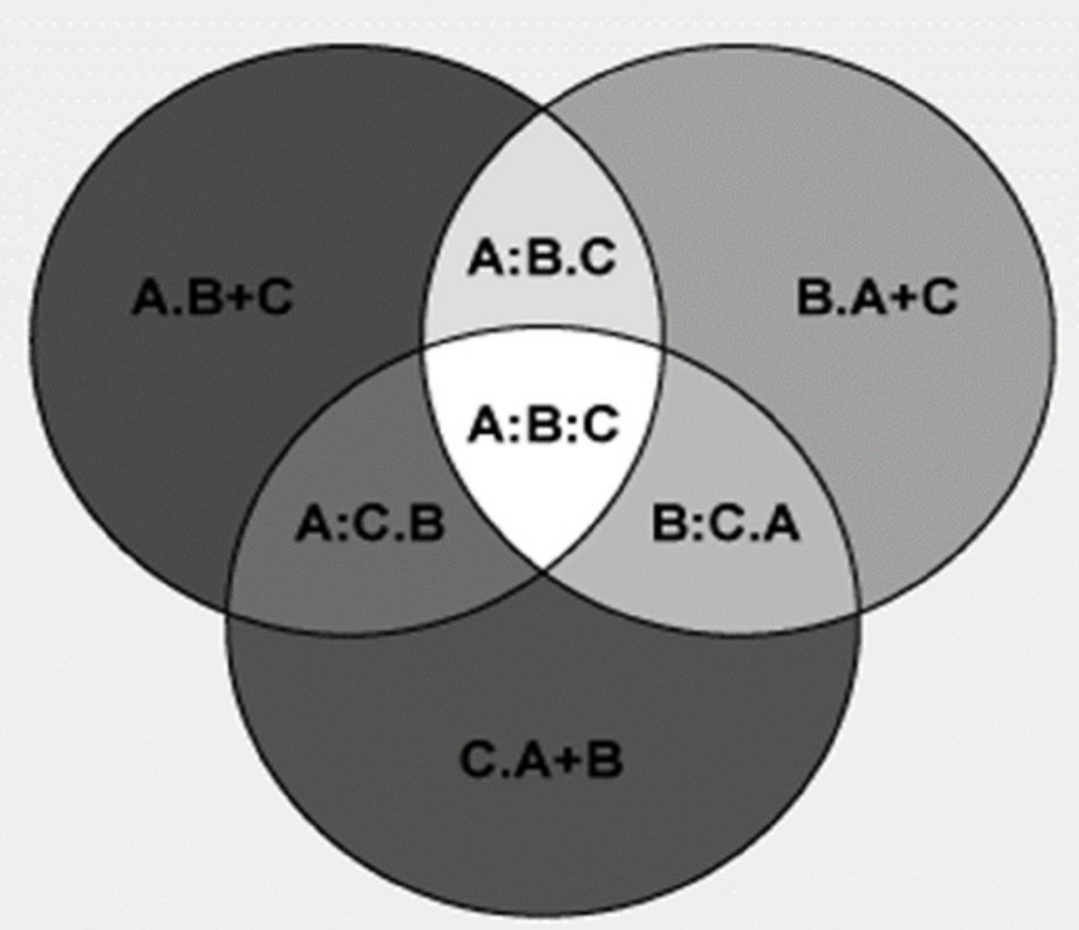

1- $(A+B+C)$ 


\section{Figure 7}

Comparing the explanatory power of MTWM, PSN and TEPMDE on the percentages of plant genera with temperate affinity by partial regression with the predictors included in the best model.

$A=0.877 ; 1-(A)=0.12 ; A . B=0.067 ; A: B=0.813 ; A . C=0.69 ; A: C=0.189 ; A . B+C=0.096 ;$

$A: B+C=0.784 ; B=0.863 ; 1-(B)=0.137 ; B . A=0.05 ; B: A=0.813 ; B . C=0.601 ; B: C=$

$0.262 ; B . A+C=0.007 ; B: A+C=0.856 ; C=0.265 ; 1-(C)=0.735 ; C . A=0.076 ; C: A=0.189$;

$C . B=0.003 ; C: B=0.262 ; C . A+B=0.032 ; C: A+B=0.233 ; A+B=0.93 ; 1-(A+B)=0.07 ;$

$A+B . C=0.697 ; A+B: C=0.233 ; A+C=0.955 ; 1-(A+C)=0.045 ; A+C \cdot B=0.099 ; A+C: B=$

$0.856 ; B+C=0.866 ; 1-(B+C)=0.134 ; B+C . A=0.082 ; B+C: A=0.784 ; A+B+C=0.962 ; 1-$

$(A+B+C)=0.038 ; A: B \cdot C=0.595 ; A: C \cdot B=-0.029 ; B: C \cdot A=0.043 ; A: B: C=0.218$

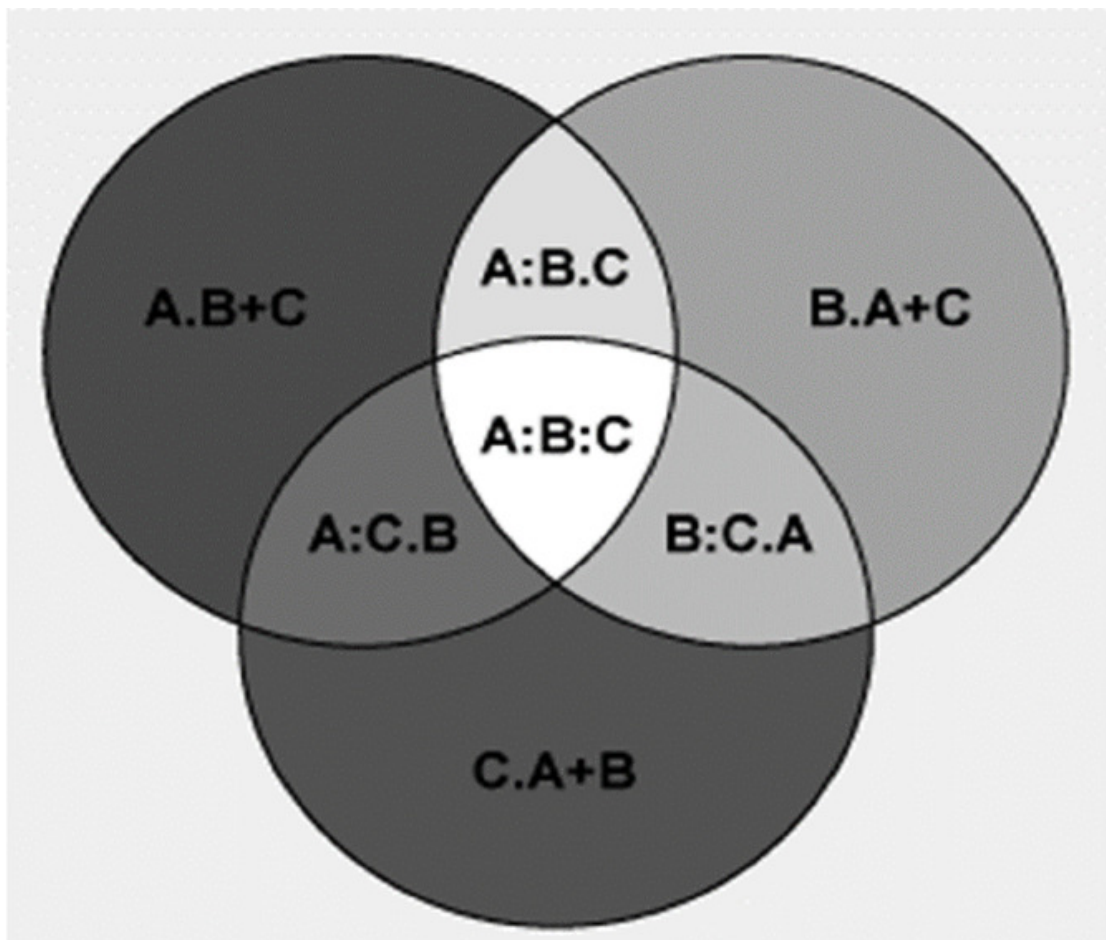

$1-(A+B+C)$ 


\section{Figure 8}

Comparing the explanatory power of climatic factors (MTWM, MAP) and the percentages generated by MDE (TEPMDE) on the percentages of plant genera with temperate affinity by partial regression with the predictors included in the best model

A shows the effects of climatic factors; $B$ shows the effects of MDE. Total variance explained by $\{A\}=93 \%$; Total variance explained by $\{B\}=26.5 \%$; Total variance explained by $\{A+B\}$ $=96.2 \%$. $[A . B]$ variance explained by $\{A\}$ only $=69.7 \% ;[A: B]$ Variance Sharely explained $=$ 23.3\%; [B.A] Variance explained by $\{B\}$ only $=3.2 \%$; $[1-(A+B)]$ Unexplained variance $=3.8 \%$

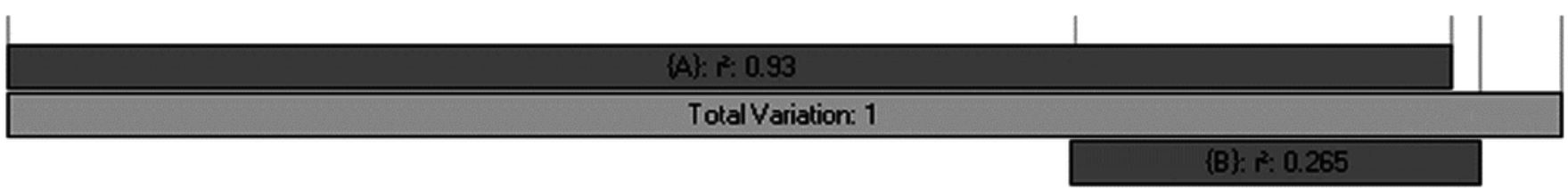




\section{Table $\mathbf{1}$ (on next page)}

Explanatory power of predictors for the percentages of tropical and temperate plants on elevational patterns through univariate regressions models (\%) 
Table 1 Explanatory power of predictors for the percentages of tropical and temperate plants on elevational patterns through univariate regressions models (\%)

\begin{tabular}{|c|c|c|c|c|c|c|}
\hline \multirow{2}{*}{\multicolumn{3}{|c|}{ Predictors }} & \multicolumn{2}{|c|}{$\begin{array}{l}\text { The percentages of } \\
\text { tropical plants }\end{array}$} & \multicolumn{2}{|c|}{$\begin{array}{l}\text { The percentages of } \\
\text { temperate plants }\end{array}$} \\
\hline & & & \multirow{2}{*}{$\begin{array}{l}\text { Explanatory } \\
\text { power (\%) } \\
98.2^{* * *}\end{array}$} & \multirow{2}{*}{$\begin{array}{c}\text { STD error } \\
0.114\end{array}$} & \multirow{2}{*}{$\begin{array}{c}\text { Explanatory } \\
\text { power (\%) }\end{array}$} & \multirow{2}{*}{$\begin{array}{c}\text { STD error } \\
0.251\end{array}$} \\
\hline \multirow{13}{*}{$\begin{array}{l}\text { Climatic } \\
\text { factors }\end{array}$} & \multirow{6}{*}{ Energy factor } & MAT $\left({ }^{\circ} \mathrm{C}\right)$ & & & & \\
\hline & & $\operatorname{MTCQ}\left({ }^{\circ} \mathrm{C}\right)$ & $97.7^{* * *}$ & 0.164 & $-82.7^{* * *}$ & 0.269 \\
\hline & & MTWQ $\left({ }^{\circ} \mathrm{C}\right)$ & $95.9^{* * *}$ & 0.219 & $-87.3^{* * *}$ & 0.231 \\
\hline & & MTDRYQ $\left({ }^{\circ} \mathrm{C}\right)$ & $96.5^{* * *}$ & 0.201 & $-83.1^{* * *}$ & 0.266 \\
\hline & & MTWM $\left({ }^{\circ} \mathrm{C}\right)$ & $94.8^{* * *}$ & 0.247 & $-87.7^{* * *}$ & 0.219 \\
\hline & & $\operatorname{MTCM}\left({ }^{\circ} \mathrm{C}\right)$ & $98.6^{* * *}$ & 0.131 & $-78.1^{* * *}$ & 0.303 \\
\hline & \multirow{4}{*}{ Water factors } & MAP (mm) & $91.3^{* * *}$ & 0.324 & $-82.1^{* * *}$ & 0.273 \\
\hline & & PWETQ (mm) & $89.5^{* * *}$ & 0.349 & $-84.6^{* * *}$ & 0.253 \\
\hline & & PDQ (mm) & $-0.019^{\mathrm{ns}}$ & 1.088 & $16.0^{* *}$ & 0.593 \\
\hline & & PWARMQ (mm) & $90.2^{* * *}$ & 0.337 & $-73.1^{* * *}$ & 0.336 \\
\hline & \multirow{3}{*}{$\begin{array}{c}\text { Seasonal } \\
\text { factors }\end{array}$} & $\operatorname{TSN}\left({ }^{\circ} \mathrm{C}\right)$ & $-57.0^{* * *}$ & 0.707 & $9.8^{* *}$ & 0.615 \\
\hline & & ART $\left({ }^{\circ} \mathrm{C}\right)$ & $-34.8^{* * *}$ & 0.870 & $0.50^{\mathrm{ns}}$ & 0.648 \\
\hline & & $\mathrm{PSN}(\mathrm{mm})$ & $71.4^{* * *}$ & 0.585 & $-86.3^{* * *}$ & 0.243 \\
\hline \multirow{2}{*}{ PMDE } & \multicolumn{2}{|c|}{ TRPMDE } & $-1.8^{\text {ns }}$ & 1.106 & $11.2^{* *}$ & 0.591 \\
\hline & \multicolumn{2}{|c|}{ TEPMDE } & $-0.3^{\text {ns }}$ & 1.098 & $26.5^{* * *}$ & 0.542 \\
\hline
\end{tabular}

MAT, the mean annual temperature $\left({ }^{\circ} \mathrm{C}\right)$; MTCQ, mean temperature of the coldest quarter $\left({ }^{\circ} \mathrm{C}\right)$; MTWQ, mean temperature of the warmest quarter $\left({ }^{\circ} \mathrm{C}\right)$; MTDRYQ, mean temperature of the driest quarter $\left({ }^{\circ} \mathrm{C}\right)$; MTWM, maximum temperature of the warmest month $\left({ }^{\circ} \mathrm{C}\right)$; MTCM, minimum temperature of the coldest month $\left({ }^{\circ} \mathrm{C}\right)$; MAP, mean annual precipitation $(\mathrm{mm})$; PWETQ, precipitation of the wettest quarter $(\mathrm{mm})$; PDQ, precipitation in the driest quarter (mm); PWARMQ, precipitation in the warmest quarter $(\mathrm{mm})$; TSN, temperature seasonality $\left({ }^{\circ} \mathrm{C}\right)$; ART, annual range of temperature $\left({ }^{\circ} \mathrm{C}\right)$; PSN, precipitation seasonality $(\mathrm{mm})$; PMDE, percentages generated by MDE; TRPMDE, tropical percentages generated by MDE; TEPMDE, temperate percentages generated by MDE. 
***, $P<0.01 ; * *, P<0.05$; ns, $P>0.05$. 